PÁGINA DEL EDITOR

\title{
Nuevos retos para la Revista Científica Ciencia Médica: Una mirada a la calidad científica
}

\author{
New challenges for Revista Científica Ciencia Médica:A look at the scientific quality
}

\author{
Hazel Vivian Soliz Alconz', Mónica Huarachi Loayza²
}

$\mathrm{L}$ as revistas científicas son una fuente principal de información en donde se publica los resultados de trabajos de investigación; el profesional en salud debe actualizarse constantemente para este fin, los artículos se han convertido en la mejor herramienta que brinda información actualizada, debe ser precisa y transparente ${ }^{1}$. Para llegar a la mayor cantidad de población, las revistas se registran a bases de datos locales, nacionales e internacionales para incrementar la visibilidad en la web, por este medio se puede acceder a revistas reconocidas que presentan artículos actuales y números anteriores. Para el registro en estas bases de datos las revistas deben cumplir con una serie de requisitos de uniformidad para presentar datos y resultados 2,3 además de los criterios de uniformidad, un grupo de expertos elaboró un conjunto de directrices para la presentación de informes como STROBE, PRISMA, STARD, CONSORT entre otros, que son exigidas por revistas como BMJ, JAMA, Lancet y NEJM'.

La "Revista Científica Ciencia Médica" nació el año 1997 desde entonces persigue el objetivo de publicar la producción científica de los estudiantes de medicina y de profesionales del área de la salud.

Con el objetivo de difundir la información generada en nuestro medio se gestionó la indización a catálogos y bases de datos gracias al esfuerzo de comités editoriales de quienes dirigidos por sus editores en jefe hicieron posibles las indizaciones, que al inicio fueron en: Latindex, IMBIOMED, Index Copernicus y las más recientes Scielo y HINARI.

Hasta ahora es notable que el recorrido de la "Revista Científica Ciencia Médica" durante estos últimos años hayan sido satisfactorios, sin embargo todavía quedan peldaños que trabajar sobre todo el aspecto de la calidad científica, siendo más concretos en lo que concierne a la "Validez científica".

Es importante considerar dentro la validez científica una serie de mitos sobre ella ya que los mismos son discordantes con el contexto objetivo que se requiere para mejorar la calidad científica. Dentro de estos están: creer que la publicación en una revista de alto prestigio garantice su validez, puesto que la lectura crítica muchas veces nos muestra que la validez de algunas publicaciones en tales revistas no logran convencer al lector; otro mito es pretender que porque los autores tengan prestigio en su práctica profesional es garantía de validez y de calidad de sus publicación, la experiencia muestra que la práctica profesional en salud no compone en modo alguno garantía de rigor metodológico y finalmente el convencimiento del investigador científico por la misma naturaleza de su trabajo, está libre de prejuicios y sesgos, pues el investigador debe ser consiente y estar listo ante el hecho de que está sometido a juicios y opiniones en pro de mejorar ${ }^{4}$.

La "Revista Científica Ciencia Médica” es resultado de mucho esfuerzo y compromiso en equipo, uno de nuestros mayores desafíos ya ha sido trazado esperamos poder continuar trabajando tomando en cuenta estas consideraciones y sin duda mantener en alto a nuestra querida revista.

\footnotetext{
${ }^{1}$ Hazel Vivian Soliz Alconz

Editora en jefe - Revista Científica Ciencia Médica, Auxiliar Titular del Departamento de Educación Medica Continua y Planificación, Sociedad Científica de Estudiantes de Medicina, Facultad de Medicina, Universidad Mayor de San Simón, Cochabamba - Bolivia.

${ }^{2}$ Mónica Huarachi Loayza

Directora de Diseño y diagramación de la Revista Científica Ciencia Médica, Sociedad Científica de Estudiantes de Medicina, Facultad de Medicina Universidad Mayor de San Simón, Cochabamba - Bolivia.

Correspondencia a:

mony-k_08_21@hotmail.com
} 


\section{EDITORIAL}

Citar como: Rev Cient Cienc Med 2014; 17(2): 3-4
Referencias:

1 Batista N, La publicación científica: Un reto necesario para los profesionales de la salud, Medicent Electrón 2014 ene.-mar.; 18(1), disponible en: http://www.medicentro.sld. cu/index.php/medicentro/article/view/1624

2 Otero P, El desafío de las publicaciones científicas: cómo seguir siendo elegidas por los lectores, Arch. Argent. Pediatr 2012; 110(5):370-371 / 370, disponible en: http://www.scielo.org.ar/pdf/aap/v110n5/v110n5a01.pdf
3 Miguel S, Revistas y producción científica de América Latina y el Caribe: su visibilidad en SciELO, RedALyC y SCOPUS, Rev. Interam. Bibliot. Medellín (Colombia) 2011; 34 (2): 187-199. Disponible en: http://eprints.rclis. org/16771/1/v34n2a6.pdf

4 Bobenrieth $M$. Normas para revisión de artículos originales en Ciencias de la Salud. Revista Internacional de Psicología Clínica y de la Salud 2002; 2 (3): 510-23

\section{LISTA DE COMPROBACIÓN PARA EL ENVÍO DE MANUSCRITOS}

- Este trabajo (o partes importantes de él) es inédito y no está siendo considerado en otras revistas.

- Se indican números telefónicos, dirección y el correo del autor responsable.

- El texto sigue el formato de la Revista Científica Ciencia Médica, de la plantilla DOT de Microsoft Word.

- El título es conciso y está en idioma español e inglés.

- Tiene un título corto que no excede de 72 carácteres.

- El trabajo no excede de 3000 palabras (originales), 3500 (revisión), 2500 (casos clínicos) y 750 (cartas al editor).

- Incluye un resumen estructurado de hasta 250 palabras (originales). Resumen no estructurado de de 150 palabras (revisión y casos clínicos).

- Las citas bibliográficas están correctamente citadas, y en su mayoría proceden de revistas o libros.

- Se envían las copias indicadas en las instrucciones para el autor en formato carta más el CD con el archivo digital del manuscrito.

\section{Informacion para el autor: Búsqueda de palabras MeSH}

1. Ingresa a: http://www.nlm.nih.gov/mash/Mbrowser.html

2. Introducir la palabra clave que se quiera comprobar.

3. Seleccionar "Descriptor"

4. Se indicará si existe o no la palabra clave seleccionada. 